\title{
A Review of Lean and Agile Management in Humanitarian Supply Chains: Analysing the Pre-Disaster and Post-Disaster Phases, and Future Directions
}

\author{
Arvind Upadhyay \\ Brighton Business School \\ University of Brighton, UK \\ a.upadhyay@brighton.ac.uk \\ Sumona Mukhuty \\ The Business School \\ Manchester Metropolitan University, UK \\ S.Mukhuty@mmu.ac.uk \\ Sushma Kumari \\ Hull University Business School \\ University of Hull, UK \\ s.kumari@hull.ac.uk \\ Jose Arturo Garza-Reyes \\ Centre for Supply Chain Improvement \\ University of Derby, UK \\ J.Reyes@derby.ac.uk \\ Vinaya Shukla \\ Business School \\ Middlesex University London, UK \\ v.shukla@mdx.ac.uk
}




\begin{abstract}
Disasters have quadrupled over the last two decades leading to unprecedented loss of life. The objective of disaster-focused humanitarian supply chains (HSCs) is to ensure saving maximum lives with limited resources; despite severe uncertainties. Therefore, significant research has investigated lean and agile in HSCs; to effectively source and speedily deploy resources, with minimum wastage; in each disaster life-cycle phase. However, the literature and research findings are currently highly disjointed regarding how lean and agile principles may be aligned with different HSC activities in the disaster management lifecycle; and do not provide a collective understanding for practitioners and researchers. This paper reviews and organises the literature on HSCs in relation to lean and agile paradigms, focusing on the pre-disaster (mitigation and preparedness) and post-disaster (response and recovery) phases. Findings reveal, all phases benefit from both lean and agile, with agile benefitting the response phase most. The phases are inter-dependent and identifying optimum decoupling points for lean and agile principles are crucial. Majority research has focused on individual or a couple of phases. Therefore, authors recommend research on integrating the functions of the different phases by employing lean and agile principles, to generate rapid response, economies of scale and cost minimisation.
\end{abstract}

Keywords: Lean, agile, disaster phases, disaster lifecycle, humanitarian supply chains, review 


\section{Introduction}

“The International Federation of Red Cross and Red Crescent Societies' (IFRC) World Disaster Report (2015) reports that between 2005 and 2014, approximately 6311 disasters resulted in 0.8 million casualties, affected 1.9 billion people, and caused $\$ 1.62$ trillion in damages" (Ransikarbum \& Mason; 2016a: 324). These circumstances are neither atypical nor rare in the humanitarian aid (HA) context. Significant injury and loss of life triggered by disasters; make it imperative to study humanitarian supply chains (HSCs) and how they can effectively contribute to the different stages of the disaster/humanitarian mission management cycle, prior and post disaster occurrence. "A natural or man-made disaster means managing ephemeral supply chains in a great hurry while trying to adhere to performance objectives" (Chandes \& Pache', 2010: 321). HA organisations are under perpetually increasing pressure to strategically use resources (Scholten, Scott and Fynes, 2010; Pettit \& Beresford, 2009), while providing high quality service to the end-user within realistic timeframes and constrained budgets. A crucial way to achieve these efficiencies while delivering high quality and value, is through effective supply chain processes, as supply chain management (SCM) accounts for $80 \%$ of HA activities (Van Wassenhove, 2006).

HA is essentially funded by donors (Kovacs \& Spens, 2007). The deliverers of HA thereby cater to dual clients: the recipient of aid and donors. Sufficient donor availability can help make HSCs agile and resilient (Dubey et al., 2014). While HA recipients seek high quality and prompt aid to save lives and restore normalcy; donors seek transparency, high value for money and measurable outputs (Scholten, Scott \& Fynes; 2010). Lack of efficiencies may result in loss of life and resultantly loss of crucial donor funds (Oloruntoba \& Gray, 2009). This challenging situation requiring trade-offs amongst speed, cost, and quality has generated research interest in principles and processes which can enhance speed, 
efficiencies, and effectiveness while reducing cost and waste in HSCs. Therefore, to enhance HSC performance (notwithstanding time and budgetary constraints) and reduce wastage; the principles of lean and agile have been found to be highly beneficial (Cozzolino, Rossi \& Conforti, 2012; Oloruntoba \& Kovacs, 2015).

Lean management is defined as the elimination or reduction of waste (or muda) in any form (Christopher \& Towill, 2001; Goldsby et al., 2006). This entails, any action, which exhausts and expends resource or energy, without yielding required outcomes for the customer (Womack \& Jones, 1996; Goldsby et al., 2006) or end-user. Lean principles help address emergent demands within short time-spans with process efficiency (Goldsby et al., 2006). This is a key focus of HA organisations as HSCs are characterised by intensive timelines, addressing specific disasters at a point in time (Chandes \& Pache', 2010). Most HA is funded by appealing to the altruistic nature of donors. Lean principles in SCM focuses on enhancing efficiencies and saving costs (Cozzolino et al., 2012). Taylor and Pettit (2009) advocate the application of lean principles like value chain analysis to enhance efficiencies of HSCs. Techniques like horizontal and vertical collaboration (Jahre \& Jensen, 2010) of leanness can also reduce spend for HA organisations. Consequently, there has been an increase in research studying lean applications in HSCs.

Agility in SCM embodies a high degree of flexibility and perpetual preparedness to react to incremental and radical change, including changes in market and customer requirements (Goldman et al., 1995; Jain et al., 2008). Agility can also; support risk management in supply chains (Faisal et al., 2007) and enhance responsiveness (Christopher \& Towill, 2000) to unpredictable change (Oloruntoba \& Gray, 2006). HSCs are characteristically involved in large-scale operations, addressing high magnitude risks to life; and need to coordinate speedy delivery of rescue and relief goods and services to disaster zones (Jabbour et al., 2017; Balcik et al., 2010; Kovacs \& Spens, 2009). HSCs are often 
emergent, with short lives; responding to specific disasters, uncertainty and mostly unforeseen situations (Day et al., 2012). HSCs need to assess and evaluate end-user needs in disaster zones and respond with speed and flexibility, to the diverse, unique and specific needs of the affected populations (Heaslip, 2018) while balancing standardisation and adaptation (Chandes \& Pache', 2010). Achieving these extensive and varied humanitarian targets swiftly, requires a high level of flexibility or agility (Heaslip, 2018). Hence, the principles of agile SCM have gained attention in relation to HSCs (Chandes \& Pache', 2010; Cozzolino, Rossi \& Conforti, 2012; Heaslip, 2018; Oloruntoba \& Gray, 2006; Oloruntoba \& Kovacs, 2015).

Authors indicate that lean and agile principles are often complementary and need integrating within the same supply chain at different points (Cozzolino et al., 2012; Goldsby et al., 2006; Narsimhan et al., 2006; Scholten et al., 2010) including HSCs (Scholten et al., 2010). In their seminal study, Naylor et al. (1999) strongly argue that lean and agility are complementary processes, which provide synergistic value in combination, compared to applying these paradigms in isolation. Applying the lean and agile principles to HSCs can help make them effective, efficient and eliminate waste simultaneously (Cozzolino et al., 2012). Lean can be instrumental in facilitating efficiencies, cost reduction and waste elimination; while agility is arguably crucial in facilitating effectiveness and speed in HSCs (Cozzolino et al., 2012). Hence, the focus of this review is on both lean and agile applications in HSCs; aimed at minimising resource waste, and enhancing flexibility, speed and delivery efficiencies, leading to ultimately saving lives.

HSC activities linked to disasters are classified into four key phases. Prior to the disaster, the focus is on 'mitigation' and 'preparedness'. Post-disaster, the focus is on 'response' and 'recovery' (McLoughlin, 1985). The entire disaster HSC lifecycle focuses on saving life, preserving life, and building and maintaining standard life quality in disaster 
zones. While studies in the last two decades have been focusing on lean and agile management in relation to HSCs - there is a need to clearly articulate how lean and agile principles are aligned with different HSC activities in the disaster management lifecycle; particularly, evaluating their effectiveness in the different pre-disaster and post-disaster phases.

In this review paper, the different ways in which lean and agile principles have been facilitated and implemented in HSCs, is examined. Most of the research has focused on an individual, or a couple of phases of the humanitarian SCM lifecycle. The literature is currently highly disjointed in terms of how lean and agile principles may be aligned with different HSC activities in the disaster management lifecycle. This review organises the literature by investigating the alignment of the HSCs with lean and agile principles and their effectiveness, in the different phases of a disaster: mitigation, preparedness, response and recovery. There is a gap between research and practical applications. This review will provide clarity to humanitarian organisations focusing on different disaster stages, aid them in prioritising their tasks and investments; and highlight crucial areas requiring further research

\section{Research Methodology}

This study employs a literature review as recommended and adopted by Tranfield et al. (2003) and Wong et al. (2012). Hereby, the evidence-informed five-step approach advocated by Denyer \& Tranfield (2009), is adopted. This involves framing the aim; detecting and identifying relevant studies; selecting and appraising studies; examining and synthesising the studies; finally reporting and using the results.

\section{Review Research Aim}

A database of the relevant articles was generated by identifying and appraising each article in 
relation to the review aim of this study. This aim is as follows:

- Evaluating the paradigms of lean and agile aligned with humanitarian supply chains, while differentiating between the four-phases of the disaster life cycle; and identifying future research directions.

\section{Detecting/Identifying Studies}

In order to identify the relevant studies, a 3-step approach was adopted: conducting a generic search in academic search engines including ABI-Inform Proquest, EBSCO Host, Scopus and Web of Science; locating articles published in journals listed in the ABS journal list and finally identifying pertinent articles from the citations in the articles identified in the first two steps. Denyer \& Tranfield (2009) advise that "the review protocol should not restrict the review and the output of the search should result in a comprehensive list of core contributions which will help address the research questions". This 3-step approach provided the widest coverage of relevant articles.

As the context of the study is HSCs, the above search engines were deemed appropriate as databases with the widest exposure in this field. In order to capture the maximum possible related articles, a few search strings were employed, which yielded 93 papers. These search strings are presented in Table 1 below.

Insert Table 1 about here

The search for this study, concentrated on peer-reviewed articles between 1985 and 2019. This review focused on the time period from 1985, as this is when the seminal article by McLoughlin (1985) was published, classifying the humanitarian aid life cycle into the four 
phases of mitigation, preparedness, response and recovery stages. Furthermore, in the last two decades work on linking lean and agile principles to HA has gained traction. Hence, the period from 1985 to the present was included in this review, to ensure the fullest coverage of relevant articles.

\section{Selecting and Appraising Studies}

The relevance of the articles were established, based on whether the search terms were present in the title and abstract of all the articles in the supply chain and logistics journals on the ABS list. The selection criteria we adopted, include the following:

- Humanitarian - the articles needed to align with humanitarian operations

- Supply Chain - the papers needed to focus on lean and/or agility in supply chain

- Disaster Phase - the article could be located in at least one of the four disaster phases

- Language - paper needed to be in English

- Journal Type - double blind, peer reviewed journals ideally included on the ABS list In addition to the 93 articles above, 10 more articles were extracted through searches in supply chain journals on the ABS list. A further 23 articles were identified via investigating citations within the articles identified in the above process. Thereby bringing the total number of articles collated initially to 126 . In the next step, duplicate journal articles from the various search engines, were removed. Articles were filtered by ensuring that the articles either made (1) a theoretical or conceptual contribution or (2) an empirical contribution. The articles were also screened based on whether they contributed to at least one of the disaster life-cycle phases. This resulted in a final number of 57 articles, which we reviewed for this study. In addition, some articles were included for supporting information. 
The articles, which formed part of the core review, are indicated with an asterisk in the reference list.

\section{Examining and synthesising studies}

Each paper was evaluated in terms of descriptive information and thematic content. The descriptive analysis adopted a more deductive style and the articles were classified based on which disaster life cycle phase the article aligned with, the year and country of author location.

Thereafter the articles were thematically analysed and classified into one or more of the four disaster life cycle phases of HSCs: mitigation and preparedness (pre-disaster stage) and response and recovery (post-disaster stage). Here a more inductive style was employed. The purpose here was to identify the different ways in which lean and agile principles could enhance effectiveness and efficiencies in each of these stages. The literature on this is disparate and disjointed, and the aim was to re-organise the literature, analyse the various approaches through which lean and agility can be achieved in these phases, and finally identify the gaps and argue future research needs, which can contribute to enhancing HSC outcomes and saving lives.

\section{Disseminating and utilising the outcomes/results}

This article is the first and primary route of disseminating these results to academia and practitioners. The following sections of this article provide the findings of this study including the descriptive analyses, thematic analyses and finally an overall analysis of the application of lean and agile paradigms to HSCs, in relation to the disaster life-cycle phases. 


\section{Descriptive Analysis: Characterising the Literature on Supply Chain in Humanitarian Operations}

The 57 articles identified for this review, was analysed in terms of the disaster lifecycle phases, year and country; to comprehend the key trends visible in the research field of lean and agile in HSCs.

The relevant articles for this review were classified into the different HSC disaster life cycle phases they pertained to. Some of the articles aligned with more than one phase (table 2). Based on this classification, it can be seen that the response phase, which is the phase directly engaged in saving lives, has received the most attention, while considering lean and agile principles.

Insert table 2 about here

The papers relevant to this review were published between 1985 and 2019. Figure 1 illustrates the number of publications each year. Publications on lean and agile management in HSCs has gained visible traction since 2006. This is attributable to the unprecedented loss of life and disruption in the aftermath of the Aceh Tsunami in 2004 and hurricane Katrina in 2005. The highest number of relevant publications are in 2010. This is consistent with the time taken in conducting and thereafter publishing academic research, which would have commenced right after the aforementioned large-scale disasters. Furthermore, a surge in HSC publications on lean and agile applications is noticeable in 2016. This may be attributed to the large-scale disasters of the Haiti earthquake in 2010 and the Japan Earthquake-TsunamiNuclear Emergency in 2011, coupled with a substantial increase in international funding for 
humanitarian and disaster relief activities around 2013 (GHA ${ }^{1}$ Report, 2016). This would have provided an impetus for research on applying lean and agile principles in HA, aimed at understanding how resources can be optimised, in developing waste-free and flexible HSCs.

Insert Figure 1 about here

Based on the location of the authors' affiliated institution, the following country map was developed (fig 2). In the country mapping, shades of deep blue highlight the countries where most publications have originated. With the highest number of authors from the USA at $28 \%$, a high level of interest is visible from USA, in lean and agile applications in HSCs. Notably, 53\% of authors publishing in this field were from Europe (including UK), also demonstrating a significantly high level of interest in lean and agile HSCs in Europe. Other countries from where academics have conducted studies on lean and agile HSCs include Australia, India, Pakistan, Thailand, Brazil and Canada.

Insert Figure 2 about here

\section{Thematic Results}

This literature review classified the content of the review articles into four major phases based on whether the focus was on the pre-disaster stage or the post-disaster stage. As

\footnotetext{
${ }^{1}$ GHA - Global Humanitarian Assistance
} 
indicated in the introduction, the pre-disaster phases are referred to as 'mitigation' and 'preparedness', while the post-disaster phases are known as 'response' and 'recovery' (McLoughlin, 1985). While this review distinguishes the literature based on the four stages of the disaster SCM life cycle, some studies address more than one stage simultaneously. The various aspects of the different studies is drawn upon in separate thematic discussions below.

This paper focuses on large-scale disasters, which are rare but of a high magnitude with the potential for long-lasting consequences, as opposed to routine emergencies. This includes: 'sudden-onset natural disasters' like earthquakes, tornadoes and hurricanes; 'slowonset natural disasters' like famine, drought and poverty; 'sudden-onset man-made' disasters like terrorist attacks, coup d'etat and chemical leaks; and 'slow-onset man-made' disasters like economic collapse, political crises and refugee crises (Van Wassenhove, 2006).

In the following sections, first each phase is defined, followed by the identification and evaluation of the core HSC research pertaining to each of these phases. Herein, this paper reviews, organises, argues and analyses how lean and agile principles have been implemented in these phases and the resultant benefits.

\section{Pre-disaster: 'Mitigation' in the Humanitarian Disaster Supply Chains}

Mitigation focuses on reducing the long-term impact of disasters, thereby attempting to reduce the extent or magnitude of loss and damage to human lives, land and property; caused by natural and man-made disasters (McLoughlin, 1985). Examples include "building codes, disaster insurance, land-use management, risk mapping, safety-codes, and tax incentives and disincentives" (McLoughlin, 1985: 166). This stage also focuses on preventing disasters (Ransikarbum \& Mason, 2016) which includes land-use controls so that high risk areas are not occupied, building barriers to swerve disaster forces, reducing the impact of ongoing/impending disasters, designing codes to enhance resistance of buildings/structures, 
negotiating tax incentives/disincentives with governments, and so on (Altay \& Green III, 2006).

With the plethora of activities crucial for disaster prevention, funding needs are high. Unfortunately, prevention activities are under-funded (Kovacs \& Tatham, 2009), and donors prefer their funds to directly benefit victims (Kovacs \& Spens, 2007; Tatham \& Pettit, 2010), thereby further constraining already constrained budgets for this phase. Hence, building in flexibility and collaboration using agile principles and eliminating any possible waste through lean principles will be extremely beneficial in this stage and ultimately save and preserve lives.

Dubey and Gunasekaran (2016) highlighted that dynamic sensing models can significantly mitigate loss of life by anticipating impending disasters beforehand, and enhancing response action, thereby incorporating agility. Bhattacharya et al. (2014) advocated investing in building infrastructure to facilitate efficient transfer mechanisms through robust networks, harnessing lean and agility. As part of studying HSC dynamic capabilities, Altay et al. (2018) investigated SC agility in the pre and post disaster phases of the HSC, and interestingly, they reported that SC agility had significant impact on predisaster performance (including mitigation). Through structural equation modelling, Dubey et al. (2015) studied the relationship between supply chain agility, adaptability and alignment on human performance and logistics performance; which they empirically tested on data collected from senior officials in the police, transport and HA organisations associated with Allahabad Kumbh, an extensively large scale religious pilgrimage festival, entailing high levels of mitigating actions against potential disasters. Based on this, Dubey et al. (2015) advocated the impact of agility and adaptability on HA performance.

L'Hermitte et al. (2015) also proposed a model by integrating various agility drivers (i.e. risks, complexities and new opportunities), agility enablers (i.e. people, processes and 
technology), speedily reactive and adaptable operations, and strategic level agility capabilities (i.e. being purposeful, action-driven, collaborative and learning-focused). They empirically tested this model on a case study of the World Food Programme (L'Hermitte et al., 2016a). Dubey and Gunasekaran (2016) advocate long-term capacity building by HSCs to be successful; including integrating information/knowledge exchange, training, speedy response and adjustability. This should help build in agility and achieve lean targets of waste reduction. Applying such models to practice, needs to commence in the pre-disaster stage to mitigate the impact on potential disasters.

Tofighi et al. (2016), focused on mitigating logistical challenges in pre- and postdisaster stages by generating a two-stage scenario-based possibilistic stochastic programming (SBPSP) system. Through this, they attempt to overcome network design issues to integrate and coordinate more efficiently between central warehouses and local distribution centres, to enhance flexibility and reduce waste. They created a differential evolution algorithm to estimate practicable solutions, within realistic time-spans; which they tested on authentic data from extant relief networks in Tehran, with favourable outcomes. Arguably, this model harnessed both agile principles for flexibility and lean principles for economisation.

Blecken (2010) adopted a modelling approach to increase the effectiveness of HSCs. Through a survey, he found, a key obstacle in HA is the lack of documentation and standardisation. Availability of this data can enhance the effectiveness of the mitigation phase. Information technology (IT) can be crucial to the humanitarian efforts (Ergun et al., 2014; Kovacs \& Spens, 2007). Blecken (2010) suggested IT infrastructure and its applications have significant potential to aid standardisation; which can lead to lean and agile outcomes of cost minimisation, transparency, and fruitful interaction between HA and endpoint users in the HSC. 
Herein, it can be seen that both agile and lean management emerge as crucial and complementary contributors to the mitigating stage in the humanitarian disaster life cycle. A strong overlap and follow-through is also visible between lean and agile activities in the mitigation and preparedness stages.

\section{Pre-disaster: 'Preparedness' in Humanitarian Disaster Supply Chains}

Preparedness entails nurturing and perfecting operational skills and resources to respond to emergencies and disasters (McLoughlin, 1985). These include, "emergency operations plans, warning systems, emergency operating centers, emergency communications, emergency public information, mutual aid agreements, resource management plans, and training and exercises" (McLoughlin, 1985: 166; Altay \& Green III, 2006). The key purpose of this stage is to minimise or escape the "gravest possible consequences of a disaster" (Cozzolino et al., 2012). Preparedness also needs to focus on network design to reduce response lag, decisionmaking models identifying locations of critical emergency supplies and developing tools to efficiently collaborate between physical and IT systems when disaster strikes (Cozzolino et al., 2012; Kovacs \& Spens, 2007). Hence, lean and agile principles are crucial to this phase.

Day et al., (2012) reported a need for 'preparedness templates' to help pre-plan for different disasters. These templates can facilitate lean, and minimise resource and cost wastage while incorporating agility. Estimations are needed to decipher the optimum level of preparedness planning; so that the pre-planning is 'forward-facing' (Day et al., 2012). This will help reduce risk, waste of time and investment costs of HA organisations. Tomasini and Van Wassenhove (2009) assert that preparing in terms of collating resources, reordering supply chains, prepositioning relief goods and postponement; is crucial for HA success. These initiatives help reap the benefits of lean and agile principles simultaneously. Gatignon et al. (2010) highlighted that preparatory actions, also help achieve lean objectives of saving 
expenses caused through 'mission creep', an occurrence whereby certain HA organisations slip into being involved with activities beyond their remit, i.e. development rather than immediate relief, leading to resource waste.

Identification of optimum location of central warehouses in the preparedness phase can help minimise waste and facilitate speed. Interestingly, nonetheless, Bhattacharya et al. (2014) found no outcome differentiation for HSC supply chains, where the aid program was entirely centralised; and those where a combination of centralised resource transfer and localised infrastructural investments were made by aid programs. This raises decision-making challenges for the agile HSC agenda. However, Tofighi et al. (2016) successfully designed a scenario-based possibilistic stochastic programme, to identify the most beneficial locations for central warehouses and local distribution centres, in anticipation of disasters (like earthquakes). In contrast to Bhattacharya et al. (2014), Tofighi et al.'s (2016) model promised to be beneficial, while also making provisions to account for ambiguous information on supply and demand, and access to transportation networks; in the aftermath of a disaster (Tofighi et al., 2016). This is arguably crucial in developing agility in the HSC and can help local authorities in decision-making and building resilience to recurring disasters like earthquakes. Similarly, Gatignon et al. (2010) also advocate decentralised HSCs based on a 10-year retrospective of the International Federation of Red Cross (IFRC) developing a decentralisation model and successfully implementing it during the Yogyakarta earthquake in 2006. Through decentralisation, these models arguably focus on reducing wastage and promoting lean in tandem with enhancing agility.

Chandes and Pache' (2010) also endorse the agile concept of 'pre-positioning' resources in anticipation and preparation for disasters, rather than passively awaiting an emergency. They propose implementing the agile 'decoupling point technique' to HSCs. They advise pre-positioning human resources and products prior to the decoupling point, in 
appropriately placed 'hubs' focusing on: "gathering and diffusion of information, ...

coordinated use of logistical resources, ... training of personnel" (Chandes \& Pache', 2010: 332). Another pre-decoupling aim is to develop standardised products, which can be subsequently tailored to specific needs of affected recipients, post the HSC decoupling point (Cozzolino et al., 2012; Shafiq \& Soratana, 2019). Van Wassenhove and Martinez (2012) also advocates the agile principle of manufacturing 'postponement' while accounting for internal and external factors, and applying operation research methodology for effective vehicle fleet management in HA. Similarly, Jahre and Fabbe-Costes (2015) showed that applying the agile engineering technique of modularity of products and survival kits, incorporating 'loose coupling' in the HSC; enhances speedy response and reduces time and finance wastage, facilitating lean outcomes. Herein the crucial complementarity of lean and agility is emphasised.

During disasters, different HA stakeholders work in parallel to deliver aid, effectively and efficiently. However, lack of coordination and collaboration can waste efforts, resources, finances and time. Successfully delivering HA, requires effective coordination amongst various stakeholders, like manufacturers, service providers, government agencies, international NGOs and different stakeholders' modus operandi (Day et al., 2012). The preparedness phase can ease coordination by building relationships, agreements and memorandums of understanding, amongst different stakeholders (Kovacs \& Spens, 2007). IT programmes and software are crucial to supporting HA coordination (Gatignon et al., 2010; Tomasini \& Van Wassenhove, 2004). All these initiatives facilitating coordination foster lean outcomes (Pettit \& Taylor, 2007) of waste elimination and agility in tandem. 
Van Wassenhove (2006) conducted case studies on the South African food crisis in 2002, IFRC in Gujarat, UNJLC ${ }^{2}$, s role in the Mozambique floods, winterisation campaign in Afghanistan; Nokia versus Ericsson; TNT $^{3}$ with the World Food Programme. He found that cross-learning between HA organisations and the private sector can significantly help develop better response strategies in the preparedness phase of the disaster HSC, fostering agility. Closer collaboration between the humanitarian organisations, businesses and academia can help to address the logistical complexities in delivering aid to populations affected by disasters, thereby harnessing both agile and lean outcomes.

Applying critical success factors to HA (Pettit \& Beresford, 2009), in particular, the preparedness and response phases (Yadav \& Barve, 2015); enhances coordination and responsiveness of HSCs. Yadav and Barve (2015) analyse the mutual relationship and power of the critical success factors, using interpretive structural modelling and cross-impact matrix multiplication. Critical success factors include: humanitarian logistics (Vitoriano et al., 2011), risk and need assessment, procurement and donation management, working with other relief agencies, capacity building of institutions and people (Pettit \& Beresford, 2009; Yadav \& Barve, 2016). This also includes robust ICT, disaster resilient infrastructure and transport facilities, strategic planning for emergency relief, government policies and organisational structure, improved forecasting, early warning systems, inventory management and continuous improvement in preparedness and response practices (Pettit \& Beresford, 2009; Yadav \& Barve, 2016). Focusing on these critical success factors in the preparedness phase, can enhance both the leanness and agility of HSCs; ultimately contributing towards waste elimination, cost effectiveness and quick response to disasters.

\footnotetext{
${ }^{2}$ United Nations Joint Logistics Centre

${ }^{3}$ Formerly known as TPG is a large logistics organisation spread across 60 countries
} 


\section{Post-disaster: 'Response’ in Humanitarian Disaster Supply Chains}

Response pertains to all activities undertaken immediately prior to, during and in the immediate aftermath of a disaster or emergency; to save human lives, reduce damage to property and enhance the post-disaster recovery process (McLoughlin, 1985). These include, "emergency plan activation, activation of emergency systems, emergency instructions to the public, emergency medical assistance, manning emergency operation centres, reception and care, shelter and evacuation, and search and rescue" (McLoughlin, 1985: 166). These also include firefighting, establishing and protecting emergency infrastructure, lifeline services recovery, managing and reducing fatalities (Altay \& Green III, 2006). Lean or avoidance of waste and agile principles or flexibility are crucial to the response phase (Cozzolino et al., 2012). The response phase in HA, benefits profusely through cost efficiencies and timely aid, while maintaining high quality. Time saved equates lives saved (Cozzolino et al., 2012) during response.

Vitoriano et al. (2011), designed a multi-criteria optimisation model for aid distribution. Barahona et al. (2013) developed a simulation and optimisation model to support relief supply distribution to affected zones, employing a multi-tier supply network. Similarly Balcik et al. (2008) brought together preparedness and response phases, and created an integrated model focusing on the final leg of the distribution chain. These models take into account; optimisation of stock, uncertainty of demand, and the rapidly changing nature of disaster response activities during an ongoing disaster; thereby exploiting both lean and agile principles.

Kovacs and Spens (2007) highlighted that sometimes the overwhelming receipt of unsolicited donated supplies cause bottlenecks at airports and warehouses, leading to waste of time, space and supplies. These include expired drugs and food, inappropriate clothing, digital goods which need electricity where infrastructures have been damaged, and incorrect 
or foreign labelling of donations. Efficiencies of lean are therefore, being achieved through; colour coding, employing local suppliers and retailers as the first port of call, joining forces in logistics, to reduce duplication and waste.

Disaster response facilities storing emergency facilities need strategic locations (Balcik \& Beamon, 2008; Jahre et al., 2016; Verma \& Gaukler; 2015) to be lean and agile. This also ties in with preparedness. Researchers encourage decision-making tools over individual knowledge (Jahre et al., 2016; Verma \& Gaukler; 2015). Identifying suitable strategic locations are challenging, as response facilities are susceptible to the same disasters, as the affected regions (Verma \& Gaukler, 2015). Simultaneously, proximity of the disaster centre, helps achieve lean. Verma and Gaukler (2015) evaluated two location modelling approaches, a deterministic accounting model for distance-dependent damages to facility and population areas, and a stochastic model built on the deterministic model, adding damage intensity as the random variable. They applied these to a case study of a large-scale earthquake in California to assess performance. Findings demonstrated that the stochastic model significantly reduced supplies costs, especially when many facilities cannot be established; manifesting lean. Charles et al. (2010) also developed a model improving agility and capabilities of HSCs. Furthermore, Tofighi et al.'s (2016) two-stage scenario-based possibilitic stochastic model, focused on generating a relief distribution plan for the response phase, drawing upon different disaster circumstances to reduce delivery times of crucial items to disaster zones, wastage, costs of unused stock and costs of outstanding demands. Hence, these models promised the desired outcomes of lean and agile management.

Humanitarian organisations usually have separate supply chains and warehouse locations for emergency response and ongoing long-term operations. Jahre et al. (2016) advocated speed and cost reduction through jointly pre-positioning warehouse locations. While Verma and Gaukler (2015), factored in damage to emergency facilities only; Jahre et 
al. (2016) integrated emergency response and post-emergency recovery facilities; factoring in difficulties of merging two supply chains, budget constraints, demand risks, infrastructure limitations, security, pilferage (due to political instability/ military operations/ civil war), colocation, relation of humanitarian organisation with governments, and accessibility. Thereby, like Verma and Gaukler (2015), Jahre et al. (2016) also developed a stochastic model. They tested it through a UNHCR ${ }^{4}$ case study coordinating two supply chains. The crucial difference in the two supply chains is that emergency response is characterised by ' $h i g h$ uncertainty' and sudden demand, unlike recovery. Therefore, response aim is to speedily purchase 'unconsigned' stock from central facilities, for transport to the affected region. The central emergency stock is pre-funded by big donors like the DFID ${ }^{5}$. In contrast, ongoing recovery operations, benefit from low 'uncertainty' and continuous demand. Hence, here consigned stock is purchased and held in country/region specific warehouses, directly from suppliers. Jahre et al.'s (2016) stochastic modelling revealed a reduction in costs and lead times, by expanding the international network design. One centre could be closed, with a slight budget increase to a different centre (e.g. closing Dubai centre and increasing Karachi centre's budget). Furthermore and crucially, Jahre et al. (2016) found synergistic benefits in combining the pre-positioning of stock for emergency response and recovery. The stochastic model showed that combining global warehouses as emergency response and recovery centres, added demand stability, justified establishing additional warehouses; while reducing lead times and the overall cost (Jahre et al., 2016). All these aspects channelled lean and agile principles in the HSCs.

Effective and speedy response also requires effective coordination (Day et al., 2012). This in turn requires agility. HA organisations have different expertise and aims (Kovacs \&

\footnotetext{
${ }^{4}$ United Nations High Commissioner for Refugees

${ }^{5}$ Department for International Development
} 
Tatham, 2009). Jahre and Jensen (2010) theoretically investigated humanitarian logistics coordination in relation to the cluster system. Clusters are based on the areas of separate functional activities for humanitarian relief. The Inter-Agency Standing Committee (IASC) (2006), a key body in coordinating humanitarian aid adopted 11 clusters: agriculture, camp coordination and management, early recovery, education, emergency shelter, emergency telecommunications, health, logistics, nutrition, protection and water/sanitation and hygiene. However, co-operation between these clusters need improvement (Hollingworth, 2009; Stoddard et al., 2007). Cluster cooperation can lead to cost-reduction and waste-reduction, thereby achieving lean outcomes.

Jahre and Jensen (2010) developed a theoretical framework presenting the trade-offs between horizontal and vertical coordination amongst clusters. Horizontal coordination entails cooperation between clusters and service providers at the same stage in the aid process or experts in similar functions. Horizontal coordination is more prevalent in HSCs and provides better access to information and tangible resources. Vertical coordination entails cooperation between service providers and clusters at different stages and points of HSCs, while focusing on the same end-user. This helps reduce overall supply chain costs and improves customer service via smoother movement along the HSC (Jahre \& Jensen, 2010). Jahre and Jensen (2010) advocated increased vertical and cross-functional coordination amongst the clusters in HSCs. Thereby they implicitly advocate flexibility and synergistic values through vertical integration. Cozzolino et al. (2012) also showed that collaboration with suppliers who can respond fastest is a preferred choice of HA organisations. These ultimately emphasise lean and agile outcomes.

Scholten et al., (2010) identify NGOs lack of investment in IT as the primary roadblock to lean and agility in HSCs. The financial dilemma is in the need to divert resources currently engaged in response, towards developing IT systems and virtual 
organisations. Yet, Scholten et al.’s (2010) findings showed that IT investment would aid effective coordination of resources and supply chains. This review argues that this would help achieve successful vertical integration recommended by Jahre and Jensen (2010). Scholten et al. (2010) also report that while achieving lean and agility, investing in sophisticated IT systems increases transparency. Donors are sceptical and demand transparency. This would help HA organisations win the limited donor funding available (Heaslip et al., 2018; Scholten et al., 2010).

Another agile phenomenon, which facilitates rapid response, is emergent temporary supply chains (TSCs) which borrow shared logistical resources (Merminod, Nollet \& Pache', 2014). TSCs respond to lack of stability and time, catering to ad-hoc projects. TSCs are disbanded on project completion and may last only a few weeks. Merminod et al. (2014) report that "TSCs require an advanced level of time and organisational stability for the human and material resources involved" (Merminod et al., 2014: 16). Humanitarian TSCs need immense agility to save maximum lives and speedily resume normalcy (Merminod et al.'s, 2014). TSCs operate based on 'anticipated responsiveness'; however the oxymoron is that for optimal effectiveness, they need to be 'prepared' for sudden-onset disasters (Merminod et al., 2014); achievable by pre-positioning resources for months or even years (Scholten et al., 2010; Verma \& Gaukler, 2015; Jahre et al., 2016; Meminod et al., 2016).

The response phase can also benefit from the decoupling point technique in HSCs (Chandes \& Pache', 2010). Pre decoupling, the HSC can focus on preparedness (discussed under preparedness) and, post decoupling, on tailoring products (like survival kits) based on specific recipient needs (depending on the nature of the disaster, religious beliefs, culture, gender etc.). Thereby the HSCs can combine lean and agile benefits. Shafiq and Soratana (2019a) also developed the lean-agile decoupling point (LADP) model based on humanitarian logistics and supply chains. Chandes and Pache' (2010) draw upon Astley \& Fombrun's 
(1983) work, recommending two distinct collective partnerships to best serve recipient needs through effective coordination and collaboration among different HSC actors. The two partnership types are direct "symbiotic partnership" in a vertical relationship and direct "commensalistic partnership" in a horizontal relationship. The former entails the emergence of a temporary chain, with organisations contributing to different parts of the chain based on their expertise; as and when required; while focusing on balancing end-recipients' needs with available supplies (Chandes \& Pache', 2010). The latter focuses on temporarily uniting and mobilising various actors and resources in the supply chain, in the immediate aftermath of a large-scale disaster. In this horizontal collaboration system; various firms offering similar human and material resources temporarily unite with the 'shared intent' of building efficiencies and collectively meeting the needs of the disaster victims (Chandes \& Pache', 2010). This review argues that employing these collaborative partnerships in the response phase would facilitate lean and agile advantages enhancing productivity.

\section{Post-disaster: 'Recovery' in Humanitarian Disaster Supply Chains}

Recovery refers to activities undertaken in the aftermath of disasters/emergencies to restore life and living conditions to minimum standards in the short-term, and normal conditions in the long-term (McLoughlin, 1985). These activities include "debris clearance, contamination control, disaster unemployment assistance, temporary housing, and facility restoration" (McLoughlin, 1985: 166). These also include financial support to government, aid organisations and affected people; reconstructing infrastructure, roads, buildings and core facilities; restoring lifeline services; providing care for displaced people, livestock and animals; organising reburial of displaced mortal remains; providing support for mental health and religious needs of affected populations (Altay \& Green III, 2006). 
The recovery stage focusing on longer-term rehabilitation entail a focal shift from emergencies to planned, routinised, repetitive HSC functions (Holguín -Veras et al., 2012) allowing opportunities to avoid waste and capitalise on lean principles of economies of scale. Here, lives are not at immediate risk, and the focus shifts from purchase-to-delivery to purchase-to-stock (Oloruntoba \& Kovacs, 2015). However, L'Hermitte et al. (2016b) demonstrates that in the short-term, the recovery stage is also fraught with uncertainties and disturbances. Hence, agile principles are beneficial in facilitating operational changes over a short time-span and ensuring continuance of HA delivery. Oloruntoba and Kovacs (2015) also emphasises the need to build-in agility to develop HSC resilience, so that HSCs can function effectively during reconstruction, in this phase.

Similar to decision-making models developed to quicken response, Ransikarbum and Mason (2016a) developed a goal-programming based tool to aid response and recovery activities 'jointly'. They employed a major Geographical Information Systems (GIS) based hazard estimation tool known as the Hazards US Multi-Hazard (HAZUS) tool (FEMA, 2014; Ransikarbum \& Mason, 2016a); analysing catastrophic sudden-onset natural disasters. The end-goal being the integration of response systems, ultimately leading to network restoration and recovery. Using this model with goal-constraints like capacity, budget and resources; revealed compromised solutions, providing flexibility and trade-offs for decision-makers. Post analysing a range of design factor permutations and combinations, Ransikarbum and Mason (2016a) reported that decision-makers can trade-off between computation time and design superiority. Barzinpour and Esmaeili (2014) created an integrated multi-objective model bringing together considerations of ideal locations for facilities versus relief distribution. Similarly, Ransikarbum and Mason (2016b) developed the MOIRR (multiple objective integrated response and recovery) model integrating supply distribution difficulties during response and restoration in the recovery phase. In this multi-criteria model, they 
incorporated a cost-based as well as equity/fairness-based solution. Arguably, these models incorporated lean principles of budget and resource constraints, while generating alternative agile solutions simultaneously.

In addition to the risk of HSC facilities being impacted by the disasters (Verma \& Gaukler, 2015), the recovery phase can also be challenged by disasters impacting the distribution infrastructure of roads, bridges and access routes to the affected locations (Liberatore et al., 2014). Liberatorie et al. (2014), analysed planning issues for repair/recovery of damaged infrastructure so that recovery phase operations and distribution activities can be continued effectively at the earliest. In order to estimate this, they apply the RecHADS model to a case study of the 2010 Haiti earthquake. Their findings emphasise the imperative of resuming efficient coordination and distribution operations at the earliest. Arguably Liberatorie et al.'s (2014) proposals help facilitate agility in the humanitarian SC recovery phase through optimisation of coordination and distribution activities.

This phase also entails reconstruction, focusing on the long-term; however, this phase suffers from lack of priority due to restricted funds (Cozzolini et al., 2012). Hence, it is crucial to eliminate waste through lean principles in this phase, to reduce costs and ensure efficiencies. Ertem et al. (2010) propose a multiple-buyer procurement auction framework for HSC management. In this framework, they consider the announcement of construction, bid construction and bid evaluation activities; in the aftermath of a disaster. This entailed identifying auction design parameters and their values, and investigating how these affected changes in auctioneer and supplier behaviours. This can also help identify appropriate and reliable suppliers to support agile outcomes in HSCs, while maintaining lean solutions in the recovery phase. 


\section{Discussion and Future Directions}

The core objective of disaster-focused HSCs is to ensure saving and preserving maximum lives. HSCs are essentially funded by altruistic donors (Kovacs \& Spens, 2007; Tatham \& Pettit, 2010), resulting in restricted funding availability (Kovacs \& Tatham, 2009). Therefore, both human and product-related resources need to be sourced speedily and deployed efficiently with minimum waste, in each disaster life-cycle phase.

The specific needs of each disaster life cycle phase, varies depending on the affected populations' religion, food habits, climate etc. This is rarely predictable in advance. Taking this into account, in the past, lean and agile principles have been employed to investigate optimum decoupling points to balance the standardised supplies and customised supplies catering to the specific needs of the affected populations (Chandes and Pache', 2010; Cozzolino et al., 2012; Shafiq \& Soratana, 2019). Lean and agile principles are highly beneficial in these HSCs. The technique of decoupling can also serve as a transition point between agility and lean.

Some researchers argued that HSCs benefit from greater alignment with lean in the pre-disaster phase and agility in the post-disaster phase (Cozzolino et al., 2012). While most of the literature on the response phase, embraces the need for agility, it is interesting to note that, Altay et al.’s (2018) study suggested that supply chain agility had no significant impact on performance post-disaster but had the most impact in the pre-disaster stage. Yet again, in contrast, Cozzolino et al.'s (2012) research showed that the post-disaster phase benefited most from agile principles. Notably, the response phase benefits the most from agile applications, the primary focus being speed, flexibility and adaptability of HA products and services as per the needs of affected populations and regions. However, our review shows that all phases benefit from both lean and agile applications. 
The entire HSC lifecycle is arguably inter-related and inter-dependent. Sporadic research has looked at developing models integrating more than one phase (e.g. Balcik et al., 2008; Barzinpour and Esmaeili, 2014; Liberatore et al., 2014; Ransikarbum and Mason, 2016a; Ransikarbum and Mason 2016b). Programmes and tools which enable joint decisionmaking across the pre and post-disaster phases (e.g. Liberatore et al., 2014; Ransikarbum \& Mason, 2016a; Ransikarbum and Mason, 2016b) incorporate agility and lean principles helping enhance speed and cost-savings. However, most research has focused on individual phases of the Humanitarian SCM lifecycle. In a few cases, research has combined a couple of phases, at the most. Both lean and agile principles will help, with the aim of making the HSC designs inherently flexible and reducing wastage. Integrating functions of the different phases will also generate economies of scale and cost reduction. Hence, the authors argue a need to focus research on integrating all four phases, particularly through decision-making tools and modelling.

Bringing together different HSC entities can enhance humanitarian actions (Ergun et al., 2014). The literature demonstrates that in the four disaster lifecycle phases; HA organisations need to work harmoniously with the separate functional activity clusters that exist for HA. These clusters include agriculture, camp coordination and management, early recovery, education, emergency shelter, emergency telecommunications, health, logistics, nutrition, protection and water/sanitation and hygiene. Attempts have been made to demonstrate how lean and agile principles can aid effective vertical and horizontal coordination and collaboration amongst these clusters; thereby reducing costs and enhancing speed (Kovacs and Spens, 2007). While lean and agile outcomes can be achieved through vertical and horizontal collaboration between different HSCs (Jahre \& Jensen, 2010); partnering up and gaining the confidence of different actors can be challenging (Day et al., 2012). Lack of cohesion can negatively impact decision-making and logistical operations 
while responding to disasters (Rodriguez-Espindola et al., 2018). Therefore, the authors argue a need to investigate how lean and agile principles can help eliminate duplication of efforts and aid activities fostering harmonious networks and working relationships, between different HSC actors.

In addition to the above; a key challenge aligned with multiple disaster phases, is the need to identify the most appropriate locations for central warehouses and the different distribution centres (Barzinpour and Esmaeili, 2014; Verma \& Gaukler, 2015). Our review shows that stochastic models and programmes are being developed to estimate optimum location points, which will reduce transport times and costs (Jahre et al., 2016; Tofighi et al., 2016; Verma and Gaukler, 2015) thereby achieving lean and agile outcomes in the long-run. Our review also revealed contradictory views and findings on optimisation, through centralisation and decentralisation of resources and warehouses (Bhattacharya et al., 2014; Gatignon et al., 2010; Tofighi et al., 2016). Lack of planning, poor decision-making and unreliable structures adversely affect HSCs, causing unnecessary waste. In such cases, aligning operational activities with centralised systems to enhance responsiveness, flexibility and collaboration can be highly fruitious (Rodriguez-Espindola et al., 2018) in harnessing lean and agility. Simultaneously, Tofighi et al., (2016) successfully implemented lean philosophy showing localised decentralisation proved to be beneficial with centralised support; as this reduces costs of excess storage and delivery and quickens response to affected zones (Tofighi et al., 2016). On reflection, the authors surmise that an optimal integration of centralisation and decentralisation is desirable for lean and agile outcomes. The estimations of this integration, facilitating lean and agility, will depend on the nature and magnitude of the disaster, geographical terrain, infrastructure resilience and generic vs. specific needs of the affected population. Therefore, advanced modelling techniques and analysis of realistic and wherever possible real time data; will be crucial to effective 
implementation of lean and agile principles, yielding speedy delivery of aid with minimum wastage.

A core issue observed through this review of the application of lean and agile principles in all the disaster phases; is the lack of availability of real data, which would be useful in developing and testing lean and agile models and frameworks. Accessing and reliably recording data from HA activities is highly challenging. Humanitarian organisations understandably, rarely collect and record data at the time of a crisis. Even where data has been recorded, minimal data $(21 \%)$ was available and most entries were incomplete (Kunz et al., 2017), making it challenging to employ in any meaningful analysis. Hence, generally HSC studies on lean and agile applications, are based on hypothetical situations, which make it challenging to extrapolate to real-life scenarios. The lack of data also makes it very challenging to assess end-point demand during crises (Day et al., 2012). Collecting and analysing data that are more accurate will enable estimation of more accurate models to help facilitate lean and agile outcomes in HSCs. This will enhance further contribution to theory and practice.

To conclude, this paper contributes to knowledge and practice, by analysing and organising the extant literature on lean and agile management in HSCs, with respect to the four phases of the disaster lifecycle. The authors evaluate similar and contradictory findings on how lean and agile applications contribute to HSCs in each phase separately. This is supplemented with an overall discussion of lean and agile applications across the four phases. Based on this review, authors identify future directions of research to bridge the gap between the current literature and practice needs. It is noted that the majority of research in this field has been confined to an individual or a couple of phases of the HSC lifecycle, at the most; and overall further research is advocated on integrating the functions of the different phases by employing lean and agile principles in HSCs. 


\section{Appendix A: List of acronyms}

ABS - Association of Business Schools

GIS - Geographical Information Systems

HA - Humanitarian Aid

HSC - Humanitarian Supply Chain

HAZUS - Hazards US

ICT - Information and Communication Technology

IFRC - International Federation of Red Cross/ and Red Crescent

IT - Information Technology

NGO - Non-Government Organisations

SCM - Supply Chain Management

TSC - Temporary Supply Chains

UNHCR - United Nations High Commissioner for Refugees

UNJLC - United Nations Joint Logistics Centre 


\section{References}

*Altay, N. and Green III, W.G., 2006. OR/MS research in disaster operations management. European journal of operational research, 175(1), pp.475-493.

*Altay, N., Gunasekaran, A., Dubey, R. and Childe, S.J., 2018. Agility and resilience as antecedents of supply chain performance under moderating effects of organizational culture within the humanitarian setting: a dynamic capability view. Production Planning \& Control, 29(14), pp.1158-1174.

Astley, W.G. and Fombrun, C.J., 1983. Collective strategy: Social ecology of organizational environments. Academy of management review, 8(4), pp.576-587.

*Balcik, B., Beamon, B.M., Krejci, C.C., Muramatsu, K.M. and Ramirez, M., 2010. Coordination in humanitarian relief chains: Practices, challenges and opportunities. International Journal of Production Economics, 126(1), pp.22-34.

*Barahona, F., Ettl, M., Petrik, M. and Rimshnick, P.M., 2013, December. Agile logistics simulation and optimization for managing disaster responses. In Proceedings of the 2013 Winter Simulation Conference: Simulation: Making Decisions in a Complex World (pp. 3340-3351). IEEE Press.

Barzinpour, F. and Esmaeili, V., 2014. A multi-objective relief chain location distribution model for urban disaster management. The International Journal of Advanced Manufacturing Technology, 70(5-8), pp. 1291 - 1302.

*Bhattacharya, S., Hasija, S. and Van Wassenhove, L.N., 2014. Designing efficient infrastructural investment and asset transfer mechanisms in humanitarian supply chains. Production and Operations Management, 23(9), pp.1511-1521.

*Blecken, A., 2010. Supply chain process modelling for humanitarian organizations. International Journal of Physical Distribution \& Logistics Management, 40(8/9), pp.675-692.

*Charles, A., Lauras, M. and Van Wassenhove, L. (2010). 'A model to define and assess the agility of supply chains: building on humanitarian experience'. International Journal of Physical Distribution \& Logistics Management, 40 (8/9): 722-741.

*Chandes, J. and Paché, G., 2010. Investigating humanitarian logistics issues: from operations management to strategic action. Journal of Manufacturing Technology Management, 21(3), pp.320-340. 
Christopher, M. and Towill, D., 2000. Supply chain migration from lean and functional to agile and customised. Supply Chain Management: An International Journal, 5(4), pp.206-213.

Christopher, M. and Towill, D., 2001. An integrated model for the design of agile supply chains. International Journal of Physical Distribution \& Logistics Management, 31(4), pp.235-246.

*Cozzolino, A., Rossi, S. and Conforti, A., 2012. Agile and lean principles in the humanitarian supply chain: The case of the United Nations World Food Programme. Journal of Humanitarian Logistics and Supply Chain Management, 2(1), pp.16-33.

*Day, J.M., Melnyk, S.A., Larson, P.D., Davis, E.W. and Whybark, D.C., 2012. Humanitarian and disaster relief supply chains: a matter of life and death. Journal of Supply Chain Management, 48(2), pp. 21-36.

*Dubey, R., Ali, S. S., Aitel, P. and Venkatesh, P. G. (2014). Mechanics of humanitarian supply chain agility and resilience and its empirical validation. International Journal of Services and Operations Management, 17 (4), pp. 367 - 384.

*Dubey, R., Singh, T. and Gupta, O.K., 2015. Impact of agility, adaptability and alignment on humanitarian logistics performance: Mediating effect of leadership. Global Business Review, 16(5), pp.812-831.

*Dubey, R. and Gunasekaran, A., 2016. The sustainable humanitarian supply chain design: agility, adaptability and alignment. International Journal of Logistics Research and Applications, 19(1), pp.62-82.

Denyer, D. and Tranfield, T., 2009. Producing a systematic review, in Buchanan, D.A. and Bryman, A. (Eds), The Sage Handbook of Organizational Research Methods, Sage, London.

*Ertem, M.A., Buyurgan, N. and Rossetti, M.D., 2010. Multiple-buyer procurement auctions framework for humanitarian supply chain management. International Journal of Physical Distribution \& Logistics Management, 40(3), pp.202-227.

*Ergun, Ö., Gui, L., Heier Stamm, J.L., Keskinocak, P. and Swann, J., 2014. Improving humanitarian operations through technology-enabled collaboration. Production and Operations Management, 23(6), pp.1002-1014.

Federal Emergency Management Agency. 2014. Hazus. [Online]. Accessed January 10, 2014. http://www.fema.gov/hazus/ 
Faisal, M.N., Banwet, D.K. and Shankar, R., 2007. Management of risk in supply chains: SCOR approach and analytic network process. Supply Chain Forum: An International Journal, 8 (2), pp. 66-79.

*Gatignon, A., Van Wassenhove, L.N. and Charles, A., 2010. The Yogyakarta earthquake: Humanitarian relief through IFRC's decentralized supply chain. International Journal of Production Economics, 126(1), pp.102-110.

GHA Report, 2016. Global Humanitarian Assistance Report, available at: www.globalhumanitarianassistance.org.

Goldman, S.L., Nagel, R.N. and Preiss, K., 1995. Agile competitors and virtual organizations: strategies for enriching the customer (Vol. 8). New York: Van Nostrand Reinhold.

*Goldsby, T.J., Griffis, S.E. and Roath, A.S., 2006. Modeling lean, agile, and leagile supply chain strategies. Journal of business logistics, 27(1), pp.57-80.

*Heaslip, G., 2018. Editorial for special issue on: humanitarian operations management. Production Planning \& Control, 29 (4), pp.1127-1129.

*Heaslip, G., Kovács, G. and Haavisto, I., 2018. Cash-based response in relief: the impact for humanitarian logistics. Journal of Humanitarian Logistics and Supply Chain Management, 8(1), pp.87-106.

*Holguín-Veras, J., Jaller, M., Van Wassenhove, L.N., Pérez, N. and Wachtendorf, T., 2012. On the unique features of post-disaster humanitarian logistics. Journal of Operations Management, 30(7-8), pp. 494-506.

Hollingworth, M. 2009. Keynote speech. 2nd International Humanitarian Logistics Symposium, Faringdon, March.

Inter-Agency Standing Committee (IASC), 2008. Annual Report 2008, Inter-agency Standing Committee. Available at: www.humanitarianinfo.org

Inter-Agency Standing Committee (IASC), 2006. Guidance note on using the cluster approach to strengthen humanitarian response. In Guidance note on using the cluster approach to strengthen humanitarian response. IASC.

*Jabbour, C.J.C., Sobreiro, V.A., de Sousa Jabbour, A.B.L., de Souza Campos, L.M., Mariano, E.B. and Renwick, D.W.S., 2017. An analysis of the literature on humanitarian logistics and supply chain management: paving the way for future studies. Annals of Operations Research, pp.1-19. 
*Jahre, M. and Fabbe-Costes, N., 2015. How standards and modularity can improve humanitarian supply chain responsiveness: The case of emergency response units. Journal of Humanitarian Logistics and Supply Chain Management, 5(3), pp.348-386.

*Jahre, M. and Jensen, L.M., 2010. Coordination in humanitarian logistics through clusters. International Journal of Physical Distribution \& Logistics Management, 40(8/9), pp.657-674.

*Jahre, M., Kembro, J., Rezvanian, T., Ergun, O., Håpnes, S.J. and Berling, P., 2016. Integrating supply chains for emergencies and ongoing operations in UNHCR. Journal of Operations Management, 45, pp.57-72.

Jain, V., Benyoucef, L. and Deshmukh, S.G., 2008. A new approach for evaluating agility in supply chains using fuzzy association rules mining. Engineering Applications of Artificial Intelligence, 21(3), pp.367-385.

*Kovács, G. and Spens, K., 2009. Identifying challenges in humanitarian logistics. International Journal of Physical Distribution \& Logistics Management, 39(6), pp.506-528.

* Kovács, G. and Spens, K.M., 2007. Humanitarian logistics in disaster relief operations. International Journal of Physical Distribution \& Logistics Management, 37(2), pp.99-114.

*Kovács, G. and Tatham, P., 2009. Responding to disruptions in the supply network-from dormant to action. Journal of Business Logistics, 30(2), pp.215-229.

*Kunz, N., Van Wassenhove, L.N., Besiou, M., Hambye, C. and Kovacs, G., 2017. Relevance of humanitarian logistics research: best practices and way forward. International Journal of Operations \& Production Management, 37(11), pp.1585-1599.

*L'Hermitte, C., Tatham, P., Bowles, M. and Brooks, B., 2016. Developing organisational capabilities to support agility in humanitarian logistics: An exploratory study. Journal of Humanitarian Logistics and Supply Chain Management, 6(1), pp.72-99.

*L'Hermitte, C., Tatham, P., Brooks, B. and Bowles, M., 2016. Supply chain agility in humanitarian protracted operations. Journal of Humanitarian Logistics and Supply Chain Management, 6(2), pp.173-201. 
*L'Hermitte, C., Bowles, M., Tatham, P. and Brooks, B., 2015. An integrated approach to agility in humanitarian logistics. Journal of Humanitarian Logistics and Supply Chain Management, 5(2), pp.209-233.

*Liberatore, F., Ortuño, M.T., Tirado, G., Vitoriano, B. and Scaparra, M.P., 2014. A hierarchical compromise model for the joint optimization of recovery operations and distribution of emergency goods in Humanitarian Logistics. Computers \& Operations Research, 42, pp.3-13.

*McLoughlin, D., 1985. A framework for integrated emergency management. Public administration review, 45, pp.165-172.

*Merminod, N., Nollet, J. and Pache, G., 2014. Streamlining humanitarian and peacekeeping supply chains: Anticipation capability for higher responsiveness. Society and Business Review, 9(1), pp.4-22.

Narasimhan, R., Swink, M. and Kim, S.W., 2006. Disentangling leanness and agility: an empirical investigation. Journal of operations management, 24(5), pp.440-457.

Naylor, J.B., Naim, M.M. and Berry, D., 1999. Leagility: Integrating the lean and agile manufacturing paradigms in the total supply chain. International Journal of production economics, 62(1-2), pp.107-118.

*Oloruntoba, R. and Gray, R., 2006. Humanitarian aid: an agile supply chain? Supply Chain Management: an international journal, 11(2), pp.115-120.

*Oloruntoba, R. and Gray, R., 2009. Customer service in emergency relief chains. International Journal of Physical Distribution \& Logistics Management, 39(6), pp.486-505.

*Oloruntoba, R. and Kovács, G., 2015. A commentary on agility in humanitarian aid supply chains. Supply Chain Management: An International Journal, 20(6), pp.708-716.

*Pettit, S. and Taylor, D., 2007. Humanitarian aid supply chain assessment: A preliminary consideration of the relevance of lean supply chain concepts to humanitarian aid supply chains. In Proceedings of the 19th annual conference for Nordic researchers in logistics, NOFOMA (pp. 881-894).

*Pettit, S.J. and Beresford, A.K.C., 2009. Critical success factors in the context of humanitarian aid supply chains. International Journal of Physical Distribution \& Logistics Management, 39(6), pp.450-468. 
*Ransikarbum, K. and Mason, S.J., 2016a. Goal programming-based post-disaster decision making for integrated relief distribution and early-stage network restoration. International Journal of Production Economics, 182, pp.324-341.

*Ransikarbum, K. and Mason, S.J., 2016. Multiple-objective analysis of integrated relief supply and network restoration in humanitarian logistics operations. International Journal of Production Research, 54(1), pp.49-68.

*Rodríguez-Espíndola, O., Albores, P. and Brewster, C., 2018. Decision-making and operations in disasters: challenges and opportunities. International Journal of Operations \& Production Management, 38(10), pp.1964-1986.

Simatupang, T.M. and Sridharan, R., 2002. The collaborative supply chain. The international journal of logistics management, 13(1), pp.15-30.

*Shafiq, M. and Soratana, K., 2019a. Humanitarian logistics and supply chain management-a qualitative study. LogForum, 15(1), pp. $19-38$.

*Shafiq, M. and Soratana, K., 2019. Lean and agile paradigms in humanitarian organizations' logistics and supply chain management. LogForum, 15(1), pp. $139-153$.

*Scholten, K., Sharkey Scott, P. and Fynes, B., 2010. (Le) agility in humanitarian aid (NGO) supply chains. International Journal of Physical Distribution \& Logistics Management, 40(8/9), pp.623-635.

Stoddard, D.A., Harmer, A., Haver, K., Salomons, D.D. and Wheeler, V., 2007. Cluster Approach Evaluation Final, OCHA Evaluation and Studies Section (ESS).

*Tatham, P.H. and Pettit, S.J., 2010. Transforming humanitarian logistics: the journey to supply network management. International Journal of Physical Distribution \& Logistics Management, 40(8/9), pp. 609-622.

*Tatham, P., Pettit, S., Charles, A., Lauras, M. and Van Wassenhove, L., 2010. A model to define and assess the agility of supply chains: building on humanitarian experience. International Journal of Physical Distribution \& Logistics Management, 40(8/9), pp. 722-741.

*Taylor, D. and Pettit, S., 2009. A consideration of the relevance of lean supply chain concepts for humanitarian aid provision. International Journal of Services Technology and Management, 12(4), pp.430-444.

*Tofighi, S., Torabi, S.A. and Mansouri, S.A., 2016. Humanitarian logistics network design under mixed uncertainty. European Journal of Operational Research, 250(1), pp.239250. 
*Tomasini, R.M. and Van Wassenhove, L.N., 2004. Pan-American health organization's humanitarian supply management system: de-politicization of the humanitarian supply chain by creating accountability. Journal of public procurement, 4(3), pp.437449.

*Tomasini, R.M. and Van Wassenhove, L.N., 2009. From preparedness to partnerships: case study research on humanitarian logistics. International Transactions in Operational Research, 16(5), pp.549-559.

Tranfield, D., Denyer, D. and Smart, P., 2003. Towards a methodology for developing evidence-informed management knowledge by means of systematic review. British journal of management, 14(3), pp.207-222.

*Van Wassenhove, L.N. and Pedraza Martinez, A.J., 2012. Using OR to adapt supply chain management best practices to humanitarian logistics. International Transactions in Operational Research, 19(1-2), pp.307-322.

*Van Wassenhove, L.N., 2006. Humanitarian aid logistics: supply chain management in high gear. Journal of the Operational research Society, 57(5), pp.475-489.

*Vitoriano, B., Ortuño, M.T., Tirado, G. and Montero, J., 2011. A multi-criteria optimization model for humanitarian aid distribution. Journal of Global optimization, 51(2), pp.189-208.

*Verma, A. and Gaukler, G.M., 2015. Pre-positioning disaster response facilities at safe locations: An evaluation of deterministic and stochastic modeling approaches. Computers \& Operations Research, 62, pp.197-209.

Womack, J. P. and Jones, D. T. (1996). Lean Thinking. Now York: Simon \& Schuster.

Wong, C., Skipworth, H., Godsell, J. and Achimugu, N., 2012. Towards a theory of supply chain alignment enablers: a systematic literature review. Supply Chain Management: An International Journal, 17(4), pp.419-437.

*Yadav, D.K. and Barve, A., 2015. Analysis of critical success factors of humanitarian supply chain: An application of Interpretive Structural Modeling. International journal of disaster risk reduction, 12, pp.213-225.

*Yadav, D.K. and Barve, A., 2016. Modeling post-disaster challenges of humanitarian supply chains: A TISM approach. Global Journal of Flexible Systems Management, 17(3), pp.321-340. 
Table 1: Search strings and resultant number of papers

\begin{tabular}{|l|l|l|}
\hline Search & Actual search settings & No of \\
& & papers \\
\hline 1 & humanitarian* OR natural disaster * OR disaster* AND lean* & 46 \\
\hline 2 & humanitarian* OR natural disaster * OR disaster* AND agile* & 22 \\
\hline 3 & humanitarian* OR disaster* AND supply chain* AND lean* & 16 \\
\hline 4 & humanitarian* OR disaster* AND supply chain* AND agile* & 9 \\
\hline & Total & 93 \\
\hline
\end{tabular}

Table 2: Articles in each Phase of the Disaster Lifecycle

Articles in each Phase of the Disaster Life-Cycle (includes double counting)

\begin{tabular}{|l|l|l|l|l|}
\hline & \multicolumn{2}{|l|}{ Pre-disaster Stage } & \multicolumn{2}{l|}{ Post-disaster Stage } \\
\hline Disaster Phase & Mitigation & Preparedness & Response & Recovery \\
\hline \multirow{2}{*}{$\begin{array}{l}\text { Number of } \\
\text { Articles }\end{array}$} & 20 & 30 & 46 & 34 \\
\cline { 2 - 5 } & *some articles aligned with multiple phases \\
\hline
\end{tabular}

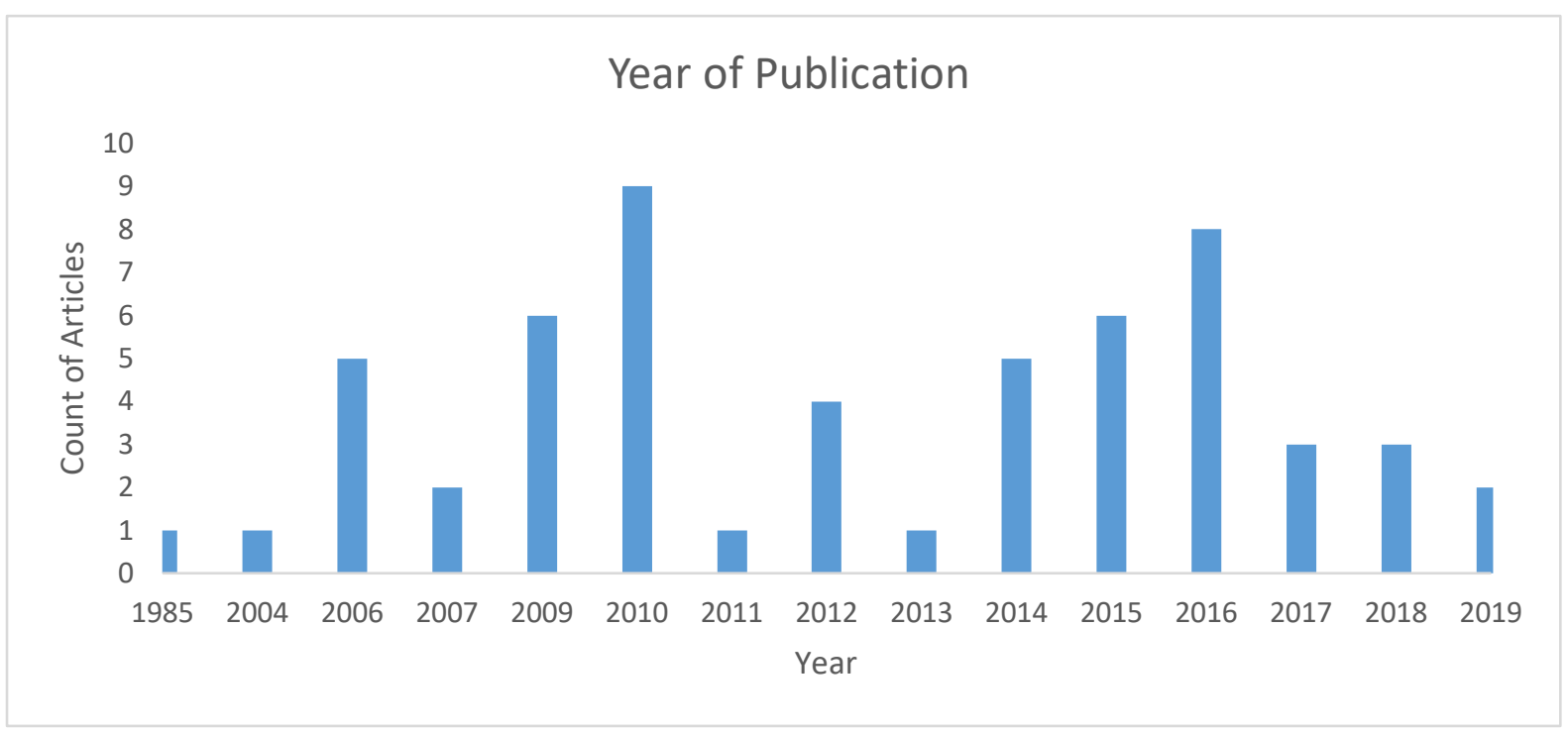

Figure 1: Number of relevant articles published each year 


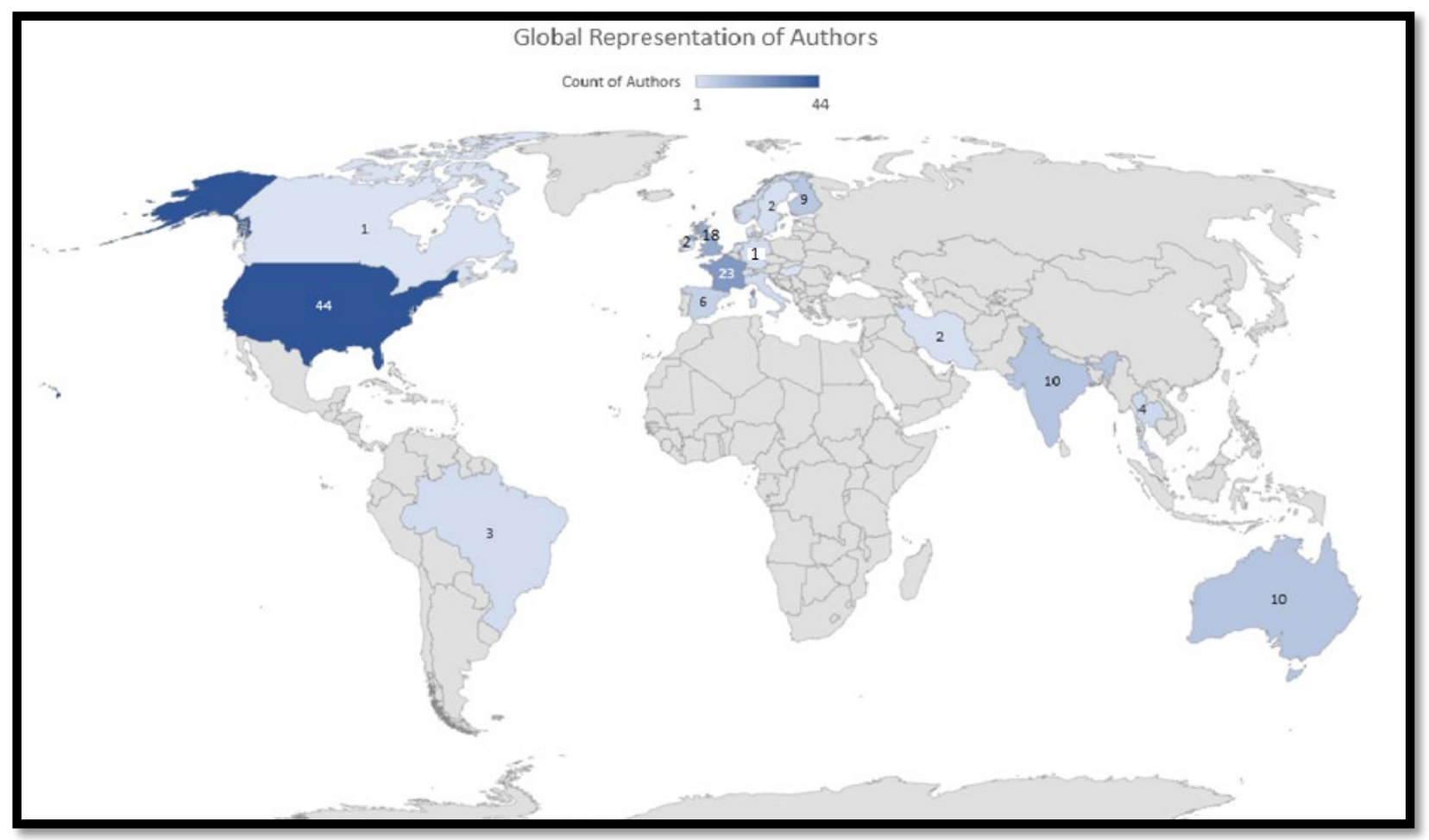

Figure 2: Location of authors publishing on lean and agile HSCs 